\title{
VIII Simposio internacional: Ética y filosofía del ser
}

Este Simposio se desarrolló en nuestra Facultad de Teología entre los días 8 y 10 de agosto. Destacan la participación de dos profesores invitados, Mariano Crespo de la Universidad de Navarra y Alejandro Bertolini de la Universidad Católica de Argentina.

La reunión fue inaugurada por Olof Page (PUC), quien destacó el valor de la interdisciplinariedad y los fines del Centro Edith Stein (CES), lo cual se refleja en la variedad de los temas abordados en el congreso.

En la primera mañana, la conferencia fue dictada por Mariano Crespo. En ella abordó el sentimiento del valor en Edith Stein, allí señaló que "Edith Stein pertenece a una generación de pensadores que intentan recuperar al mundo de los sentimientos del descrédito en el que habia caído señalando incluso la relevancia axiológica que estos presentan. Dicha recuperación tiene como punto de origen la filosofía de Franz Brentano, especialmente, su distinción entre tres tipos de fenómenos psíquicos: las representaciones, los juicios y los fenómenos de interés, emociones, o fenómenos de amor y odio". Explicó la importancia de las consideraciones axiológicas estudiadas por la fenomenóloga alemana. Posteriormente Pamela Chávez (PUC) se refirió a los fundamentos ontológicos para una ética del trato con el mundo natural, según Edith Stein.

La tarde se dedicó a los desafíos planteados desde el concepto de libertad y de la tradición tomista por parte de Mariano de la Maza (PUC) y María Esther Gómez (UST), quienes proporcionaron pistas en la comprensión ética del pensamiento steiniano.

El segundo día -memoria litúrgica de Teresa Benedicta de la Cruz- las ponencias se dedicaron al ámbito teológico. La primera, de Alejandro Bertolini, profundizó en los conceptos "entrega", "alteridad" e "identidad" en clave steiniana, a partir de una "comprensión del ser", que reconfigura radicalmente la concepción de estos conceptos y los proyecta a un orden trinitario. Luego, Anneliese Meis 
(PUC), presentó su estudio "El bonum siempre mayor y su relevancia ética, según Edith Stein". Cabe destacar la siguiente afirmación de la profesora Meis, en ella aborda el tema central de este simposio: "Cuando Edith Stein se refiere al bonum en Acto y Potencia VI 23g, hace uso de una noción antiquisima de raigambre platónico-dionisiana, concretada en su relevancia ética por el axioma aristotélico "el bien solo se obtiene desarrollando su propia esencia» axioma que como tal constituye el fundamento de aquella disciplina filosófica que se denomina Ética en razón de ocuparse de "todo cuanto en nuestra vida está relacionado con el bien y con el mal'. En este mismo sentido, Andrés Ferrada (PUC) presentó algunos fundamentos bíblicos implícitos en la obra Potenz und Akt: Este aseveró que el pensamiento steiniano constituye "una auténtica filosofía cristiana que, ante los desafios que atravesaba el cristianismo en el contexto particular de la Alemania de los años 20 y 30 del siglo pasado, inserta las respuestas profundas que requerian en la polaridad Intelligo ut credam -entiendo para creer-y Credo ut intelligam-creo para entender-. No suprime la tensión eliminando uno de los polos, sino los integra, desde la convicción ( $f e$ y la constatación del fenómeno (razón) de la paradoja del hombre y del misterio de Dios".
La mañana finalizó con la Eucaristía, presidida por Mons. Cristián Roncagliolo, quien recordó el valor del pensamiento espiritual de la autora.

Durante la tarde, Cristina Bustamante (PUC) presentó la ponencia "Tópicos antropológico-teológicos para una ética narrativa" donde estableció un nexo con el pensamiento de Paul Ricoeur en el ámbito de la praxis literaria. La jornada concluyó con una lectura dramatizada, de las actrices Maureen Boys y Elsa Poblete, del guión "Medianoche" de Florencia Martínez, inspirada en el "Diálogo Nocturno" de la filósofa carmelita. Esta obra es fruto del Proyecto Interdisciplinar "Diálogo Nocturno de Edith Stein, VRI-UC Arte y Teología 2016-2017”.

El día jueves fue dedicado a las Bellas Artes: Juan Francisco Pinilla profundizó en la obra teatral "Medianoche" a partir de su exposición sobre el Nächtliche Zwiesprache de Edith Stein. Presentó este trabajo llevado a cabo en conjunto por varios académicos, cuya importancia destacó así: "Cabe preguntarse si el arte en si mismo, como poetización de la existencia, no es justamente el grito ético auténtico del corazón humano, un Guernica silencioso y elocuente. $Y$ esto acontece no en la claridad del día, del bien, del deber 
o del valor, supuestos en su inmutabilidad trascendente, sino en el combate de la noche "que amenaza con tragarlo todo", cuando el sentido de todas las cosas se desvanece en una sombra igualadora y sobre todo amenaza con borrarnos a nosotros mismos. Diálogo Nocturno nos presenta entonces un ética de los suplicantes, de los que apuestan por un sentido oculto y por eso trascendente, lo que podemos llamar una "ética teológica negativa». Por su parte, Saide Cortés (PUC) relacionó Letras y Ética en su estudio "La perversidad en cuentos de Edgar Allan Poe" y Eva Reyes (UCN) presentó "Fausto y el Eterno Femenino. Una lectura ética desde Edith Stein". Ambos trabajos reforzaron el carácter pedagógico de la literatura pensado desde la teología.

Fernando Berríos (PUC) se refirió a la Teología sacramental y sus retos éticos. El investigador afirmó: "Está claro, con todo esto, que Edith Stein entendió muy profundamente que el alcance de la oración en cualquiera de sus formas en el ámbito de la praxis cristiana, es un momento interno y necesario de la obra de la redención que Dios opera, en Cristo, con Él y en Él, en cada creyente". Las tres ponencias anteriores se vieron sintetizadas en los alcances semióticos de F. Berríos. Finalmente, la doctora Rosa Walker (PUC) estableció un nexo con la medicina desde una experiencia narrativa-ética. Para concluir el Simposio, el Profesor Mariano Crespo ofreció una síntesis que profundizó el sentido de la interdisciplinariedad llevada a cabo por el Centro.

El Simposio incluyó un seminario abierto, que esta vez en coincidencia con el tema del Simposio, tuvo por tema "Introducción a la Ética de Edmund Husserl". M. Crespo ofreció una selección de textos de las Vorlesungen. Se pudo apreciar la evolución del pensamiento de Husserl en sus Lecciones sobre ética y teoría del valor.

El esfuerzo del Simposio es un aporte a la investigación, que objetivo primordial del CES, para fomentar la reflexión interdisciplinaria sobre temas significativos para la teología, la Iglesia y la sociedad, a partir del pensamiento de Edith Stein.

Juan Francisco Pinilla Pontificia Universidad Católica de Chile 
